\title{
Sodium, Calcium, and Magnesium Levels in Nails of Children with Cystic Fibrosis of the Pancreas
}

\author{
P. J. LEONARD and W. P. MORRIS \\ From the Department of Biochemistry, Trinity College, Dublin
}

\begin{abstract}
Leonard, P. J., and Morris, W. P. (1972). Archives of Disease in Childhood, 47, 495. Sodium, calcium, and magnesium levels in nails of children with cystic fibrosis of the pancreas. Nail sodium, calcium, and magnesium levels were measured in 15 children with cystic fibrosis (CF) of the pancreas and compared with values found in 78 controls. There was a significant increase in the mean value of all three parameters in the CF group. There was an overlap in the values between the affected and control groups for all three measurements. Summing the sodium and calcium values or the sodium, calcium, and magnesium values gave a clear-cut separation between the groups, this being better in the latter case. It is felt that this approach might also prove fruitful in the detection of the heterozygote.
\end{abstract}

The incidence of $\mathrm{CF}$ of the pancreas has been reported as ranging from 1 in 400 to 1 in 4000 live births (Roberts, 1960; Steinberg and Brown, 1960; Honeyman and Siker, 1961; Pugh and Pickup, 1967; Hall and Simpkiss, 1968). Thus it is one of the commonest inherited defects in infants. Sweat sodium levels are raised in CF of the pancreas and this measurement has been used extensively as a means of detection (Gibson and Cooke, 1959; Goldbloom and Sekelj, 1963; Warwick, 1966; Friedlander, Gasber, and Lieb, 1969). Raised levels of sodium were found in the nails of children with CF of the pancreas by Kopito et al. (1965), Shwachman and Kopito (1967), and Bock et al. (1967). Due to overlap in the levels found in CF children with those in healthy children, the usefulness of the nail test is confined almost exclusively to cases with clinical features of the disease and borderline sweat sodium levels.

In addition to the raised sodium levels observed in sweat and nails, a raised calcium level in submaxillary saliva has also been noted (Chernick, Barbero, and Parkins, 1961; Gugler et al., 1967; Mandel et al., 1969). This raised the question as to whether electrolyte abnormalities other than that of sodium existed in the nails of children with CF of the pancreas which may possibly enhance the diagnostic value of nail analyses. The advantages of such analyses as a screening technique are the ease of collection, storage, and transport of material

Received 10 January 1972. obviating the need to bring the patient to a specialist centre or bring sensitive electronic equipment to the patient. In the present study nail sodium, calcium, and magnesium levels were measured in children with CF of the pancreas, in children in hospital, and in healthy controls.

\section{Materials and Methods}

Nail clippings were collected from 93 children. These included 56 healthy children whose ages ranged from 6 months to 14 years, with a mean age of 5.3 years, 22 children who were admitted to hospital for a variety of reasons, whose ages ranged from 6 months to 10 years, with a mean age of $4 \cdot 1$ years, and 15 known fibrocystics whose ages ranged from 6 months to 6 years, with a mean age of $3 \cdot 2$ years. After drying to a constant weight the nails were got into solution essentially as described by Kopito et al. (1965). Calcium and magnesium levels were determined fluorometrically as described by Schachter (1959) and Phillips and Elevitch (1966), respectively. Sodium was measured by flame photometry.

\section{Results}

The mean results for the different groups are presented in Table I, and illustrated in Fig. 1 to 3. It can be seen that there was no significant difference observed between the mean values found in the healthy children and those in hospital for any of the parameters measured. There was a significant rise in the mean sodium, calcium, and magnesium levels in the fibrocystic group. Looking at 
the distribution of the values found for each parameter separately, it is seen that there was an overlap

TABLE I

Mean Results from Analysis of Nail Clippings of 93 Children

\begin{tabular}{|c|c|c|c|c|}
\hline Group & No. & $\begin{array}{c}\text { Sodium } \\
\mu \mathrm{g} / \mathrm{mg} \pm \\
\text { SD) }\end{array}$ & $\begin{array}{c}\text { Calcium } \\
(\mu \mathrm{g} / \mathrm{mg} \pm \\
\mathrm{SD})\end{array}$ & $\begin{array}{c}\text { Magnesium } \\
(\mu \mathrm{g} / \mathrm{mg} \pm \\
\mathrm{SD})\end{array}$ \\
\hline $\begin{array}{l}\text { Controls } \\
\text { Hospitalized } \\
\text { Fibrocystic }\end{array}$ & $\begin{array}{l}56 \\
22 \\
15\end{array}$ & $\begin{array}{r}3 \cdot 34 \pm 1 \cdot 40 \\
3 \cdot 67 \pm 0 \cdot 46 \\
9 \cdot 12 \dagger \pm 3 \cdot 20\end{array}$ & $\begin{array}{r}3 \cdot 64 \pm 1 \cdot 77 \\
3 \cdot 82 \pm 1 \cdot 35 \\
9 \cdot 96+ \pm 3 \cdot 70\end{array}$ & $\begin{array}{r}3 \cdot 45 \pm 1 \cdot 50 \\
3 \cdot 41 \pm 1 \cdot 76 \\
4 \cdot 72^{\star} \pm 1 \cdot 45\end{array}$ \\
\hline
\end{tabular}

Note: When compared with control group, $\star=\mathbf{P}<0.01$, $t=\mathrm{P}<0.001$.

with the control group, being least for sodium and greatest for magnesium. Thus the diagnostic value of any one of these measurements on its own is greatly reduced. As there was a significant increase in the mean values for all three parameters, it was felt that a combination of these values might result in a clear-cut separation between the control and fibrocystic groups. In Fig. 4 the combined $\mathrm{Na}+\mathrm{Mg}, \mathrm{Na}+\mathrm{Ca}$, and $\mathrm{Na}+\mathrm{Ca}+\mathrm{Mg}$ values are plotted for the groups. The control and hospital groups were combined for this exercise, as no significant difference was noted between them.

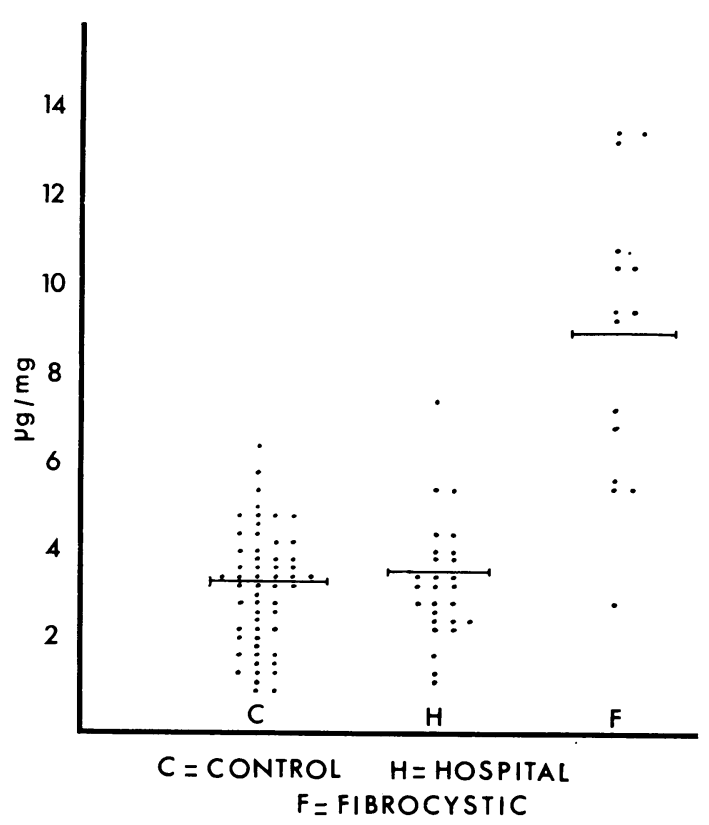

FIG. 1.-Sodium levels in nails.

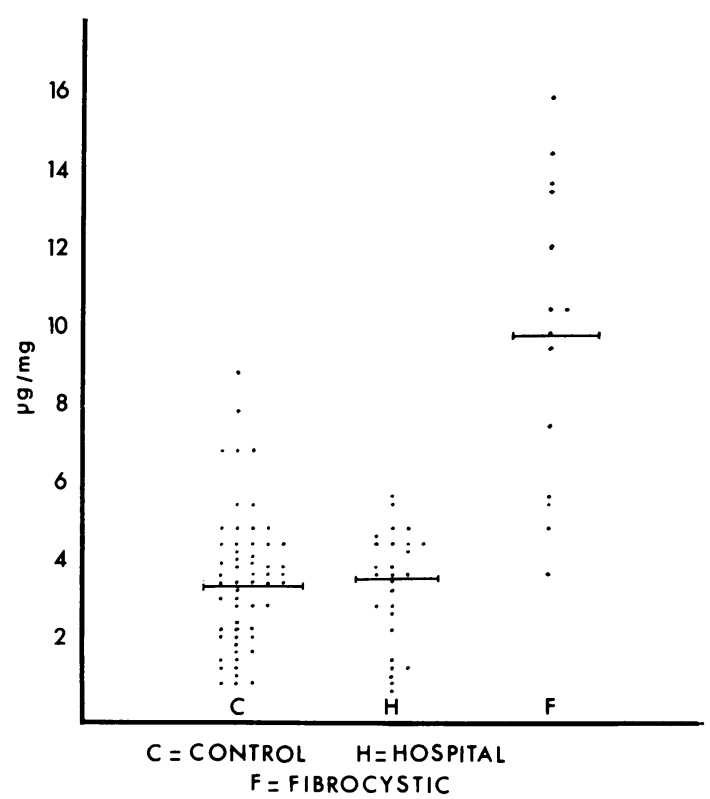

FIG. 2.-Calcium levels in nails.

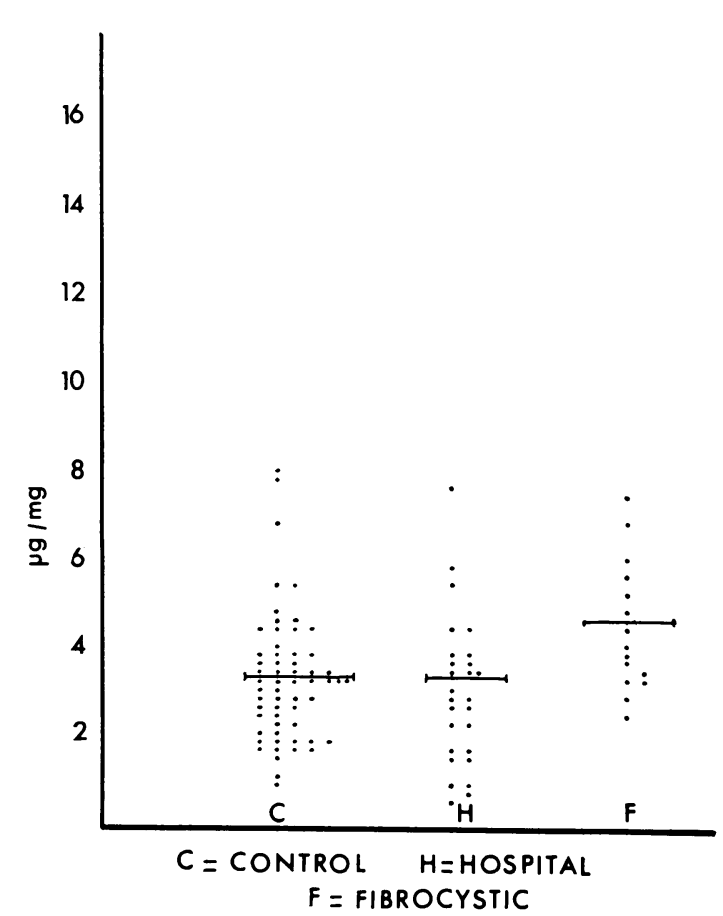

FIG. 3.-Magnesium levels in nails. 


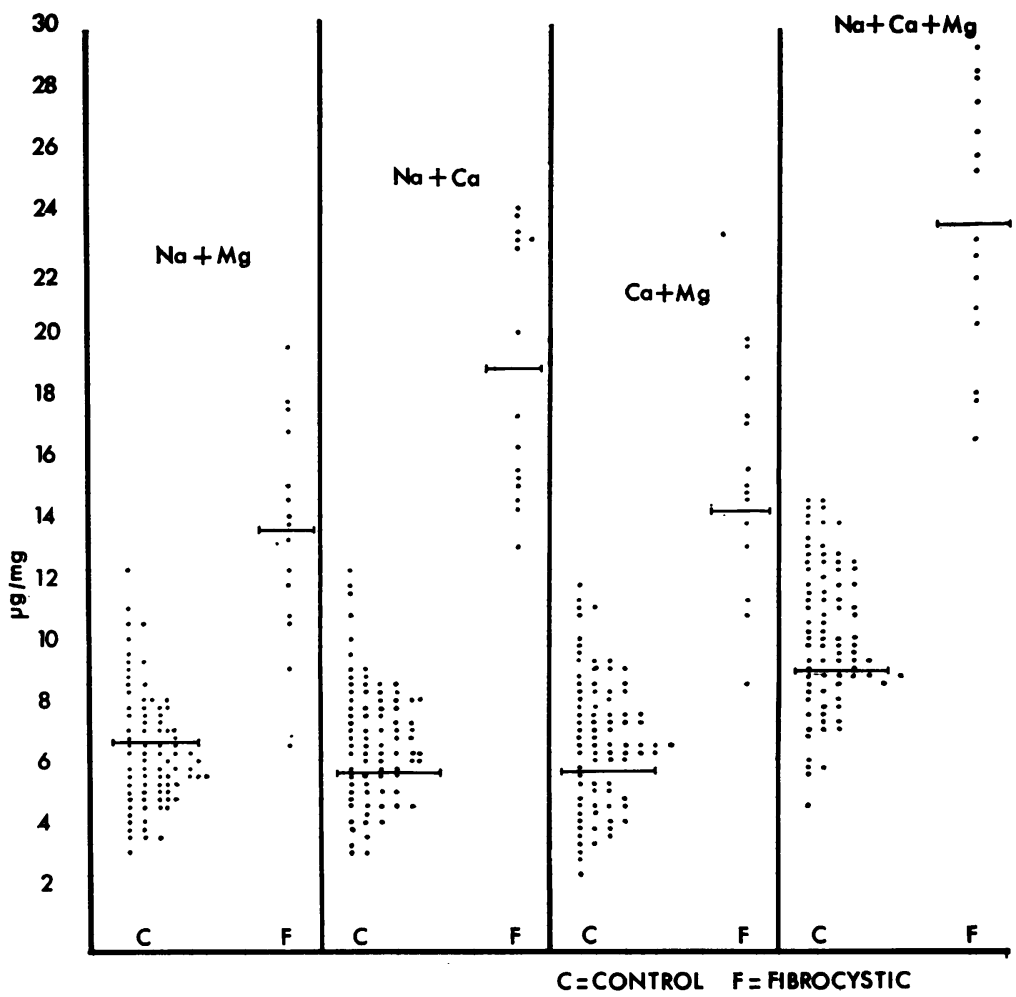

FIG. 4.-Effect of summing the various electrolyte concentrations on the diagnostic value of nail electrolytes in $C F$ of the pancreas.

It can be seen that summing the sodium and magnesium values did not completely separate the fibrocystic group from the controls, whereas summing the sodium and calcium values or the sodium, calcium, and magnesium values did. A better separation was achieved when all three values were combined.

\section{Discussion}

The present study confirms the finding of a raised mean sodium level in the nails of children with fibrocystic disease of the pancreas but with some overlap with the normal range as described previously (Kopito et al., 1965; Shwachman and Kopito, 1967; Bock et al., 1967). An additional finding is the raised levels of both calcium and magnesium, which does not appear to have been noted previously. It is felt that the diagnostic significance of nail electrolyte analysis is greatly enhanced by this observation as summation of the sodium, calcium, and magnesium levels leads to a clear-cut separation between the fibrocystic and control groups. Thus at least for children over 6 months, there being none under this age in the group studied, this might prove to be a very simple and efficient screening technique. It would, however, have to be evaluated in this younger age group as it cannot be validly inferred that the same range of values would be found in healthy children of this age. For example, Lawson, Saggers, and Chapman (1967), measuring the sodium concentration of unstimulated parotid saliva, found a clear-cut separation between values found in 5 children with fibrocystic disease who were aged 3 to 4 months when compared with normal children of the same age. When compared with values obtained for children ranging from 1 day to 6 weeks, however, there was a big overlap.

It has been suggested that as many as 1 person in 16 may carry the gene for CF of the pancreas (Shwachman and Kopito, 1967). Detection of the heterozygote is therefore desirable. To date there appears to be no simple test which is useful in detecting the heterozygote. Sweat or parotid 
sodium levels which are useful in detecting the homozygote appear to be of little use in identifying the heterozygote (Saggers et al., 1967; Shwachman and Kopito, 1967). The results of the present study show the advantage of measuring nail sodium, calcium, and magnesium levels over nail sodium levels on their own in detection of the homozygote. It is suggested that this approach might also prove useful in the detection of the heterozygote.

The authors wish to thank Dr. R. Rees of the National Children's Hospital, Harcourt Street, and Dr. B. Stokes of Royal City of Dublin Hospital, Baggot Street, Dublin, for providing some of the nail specimens used in this study.

\section{REFERENCES}

Bock, H., Koch, E., Stephan, U., Windorfer, A., Sitzmann, F. C., and Grosse, H. (1967). Investigations on electrolyte concentrations in the nails of cystic fibrosis patients and controls. Modern Problems in Pediatrics, 10, 279.

Chernick, W. S., Barbero, G. J., and Parkins, F. M. (1961). Studies on submaxillary saliva in cystic fibrosis. Fournal of Pediatrics, $59,890$.

Friedlander, S., Gasber, R. E., and Lieb, L. M. (1969). Cystic fibrosis of the pancreas. Diagnosis by sodium electrode sweat tests. California Medicine, 110, 367.

Gibson, L. E., and Cooke, R. E. (1959). A test for concentration of electrolytes in sweat in cystic fibrosis of the pancreas utilizing pilocarpine by iontophoresis. Pediatrics, 23,545 .

Goldbloom, R. B., and Sekeli, P. (1963). Cystic fibrosis of the pancreas: diagnosis by application of a sodium electrode to the skin. Nerv England fournal of Medicine, 269, 1349.

Gugler, E., Pallavicini, C. J., Swerdlow, H., and di Sant' Agnese, P. A. (1967). The role of calcium in submaxillary saliva of patients with cystic fibrosis. Fournal of Pediatrics, 71, 585.
Hall, B. D., and Simpkiss, M. J. (1968). Incidence of fibrocystic disease in Wessex. Fournal of Medical Genetics, 5, 262.

Honeyman, M. S., and Siker, E. (1961). Cystic fibrosis of the pancreas. Genetic review and estimate of incidence. Con- $\vec{D}$ necticut Health Bulletin, 75, 275.

Kopito, L., Mahmoodian, A., Townley, R. R. W., Khaw, K. T., 으 Shwachman, H. (1965). Studies in cystic fibrosis. Analysis o of nail clippings for sodium and potassium. New England $\overline{\bar{\omega}}$ Fournal of Medicine, 272, 504.

Lawson, D., Saggers, B. A., and Chapman, M. J. (1967). Screening $\overparen{D}$ for cystic fibrosis by measurement of unstimulated parotid saliva sodium levels. Archives of Disease in Childhood, 42, 689. के

Mandel, I. D., Eriv, A., Kutscher, A., Denning, C., Thompson, R. H., Jr., Kessler, W., and Zegarelli, E. (1969). Calcium and $\vec{O}$ phosphorus levels in submaxillary saliva: changes in cystic fibrosis and in asthma. Clinical Pediatrics, 8, 161.

Phillips, R. E., and Elevitch, F. R. (1966). Progress in Clinical Pathology, Vol. 1, p. 62. Ed. by M. Stefanini. Grune and Stratton, New York.

Pugh, R. J., and Pickup, J. D. (1967). Cystic fibrosis in the Leeds ? Region: incidence and life expectancy. Archives of Disease $\sharp$ in Childhood, 42, 544.

Roberts, G. B. S. (1960). Familial incidence of fibrocystic disease $\mathrm{N}$ of the pancreas. Annals of Human Genetics, 24, 127.

Saggers, B. A., Lawson, D., Stern, J., and Edgson, A. C. (1967) Rapid method for the detection of cystic fibrosis of the pancreas of in children. Archives of Disease in Childhood, 42, 187.

Schachter, D. (1959). The fluorometric estimation of magnesium 을 in serum and in urine. Fournal of Laboratory and Clinical Medicine, 54, 763.

Shwachman, H., and Kopito, L. (1967). Some genetic considerations in cystic fibrosis: a study of nail and sweat sodium in two sibships. Acta Paediatrica Scandinavica, 56, Suppl. 172, 192.

Steinberg, A. G., and Brown, D. C. (1960). On the incidence of cystic fibrosis of the pancreas. American fournal of Human $\vec{\omega}$ Genetics, 12, 416.

Warwick, W. J. (1966). Cystic fibrosis sweat test for newborns. N fournal of the American Medical Association, 198, 59.

Correspondence to Dr. P. J. Leonard, Department of Clinical Chemistry, Searle Scientific Services, Lane End Road, High Wycombe, Bucks. 